\title{
E-Learning and Social Media Motivation Factor Model
}

\author{
Mohd Shafie Rosli ${ }^{1}$, Nor Shela Saleh ${ }^{2}$, Baharuddin Aris ${ }^{1}$, Maizah Hura Ahmad ${ }^{3}$, Abbas Abjoli Sejzi $^{1}$ \& \\ Nur Amalina Shamsudin ${ }^{1}$ \\ ${ }^{1}$ Faculty of Education, Universiti Teknologi Malaysia, Johor Bahru, Malaysia \\ ${ }^{2}$ Faculty of Management, Universiti Teknologi Malaysia, Johor Bahru, Malaysia \\ ${ }^{3}$ Faculty of Sciences, Universiti Teknologi Malaysia, Johor Bahru, Malaysia \\ Correspondence: Mohd Shafie Rosli, Faculty of Education, Universiti Teknologi Malaysia, Johor Bahru, \\ Malaysia. E-mail: shafierosli@utm.my
}

Received: April 8, 2015 Accepted: June 13, 2015 Online Published: December 28, 2015

doi:10.5539/ies.v9n1p20 URL: http://dx.doi.org/10.5539/ies.v9n1p20

\begin{abstract}
The aims of this study are to probe into the motivational factors toward the usage of e-learning and social media among educational technology postgraduate students in the Faculty of Education, Universiti Teknologi Malaysia. This study had involved 70 respondents via the means of a questionnaire. Four factors have been studied, named, the factor of technology, exposure, content and social influence. Via Structural Equation Modeling (SEM), this research uncovers that respondents usage of e-learning is being motivated by the factor of technology and content. The respondents use of social media was found to be motivated by the factor of technology and social influence. A strong positive relationship exists between the usage of e-learning and social media suggesting that social media can be manipulated as supporting material for e-learning. Yet, the finding may not be generalized to all Malaysian educational technology postgraduate students.
\end{abstract}

Keywords: structural equation model, Spearman's rho, e-learning, social media, motivational factors, postgraduate students, educational technology

\section{Introduction}

The advancement of technology nowadays had impacted the way education being approached globally. Begun with the incorporation of computer into the classroom and now with the heavy integration of the Internet into the education system, educational landscape had changed for good (Mosher, 2005). E-learning enable students to operate their own learning according to their self-directed ability with the authority to select their own venue, time, content as well as the direction of their study (Jamaludin, 2000; Rosenberg, 2001; Shea-Schultz \& Fogarty, 2002). In addition, e-learning give place for asynchronous communication (El-Seoud et al., 2013; Giesbers et al., 2014) and synchronous communication (Marco, Penichet, \& Gallud, 2013; Lesko Jr., 2012).

Besides e-learning, the Internet also fetched in the social media along. As impact, the social networking sites become vastly widespread regardless of geographical boundaries as well as cultural curtain (Pumper, Yaeger, \& Moreno, 2013). Facebook is the most popular social networking site with approximately 1 billion users globally (Socialbakers, 2012).

As the educational technology evolves throughout the new millennium, the e-learning and social media has been heavily integrated into the educational approach (e.g. Sozcu, 2014; Stein et al., 2014; Gewerc, Montero, \& Lama, 2014). E-learning has been adopted by higher education institution as a tool for supporting professional development and continuing education (King \& Boyatt, 2014). At the same time, social media has been implemented as a bridge of continuing and seamless communication between instructor and students as well as between student and student in higher education (Magogwe, Ntereke, \& Phetlhe, 2014). To further strengthen the effectiveness of e-learning and social media, the motivational factor of its usage has to be unfolded. A number of research on the motivational factors of e-learning usage and social media usage has been conducted. Yet, limited research exists on the motivational factors of e-learning and social media usage in an educational technology course in South-East Asia especially in Malaysia. 


\section{Literature Review}

\subsection{E-learning Usage Motivational Factors}

Several factors have been forwarded as motivational factors to e-learning usage. The new landscape of education due to the diffusion of digital technologies had made technology as one of the main components in setting up the benchmark for e-learning (Castillo-Merino \& Serrradell-Lopez, 2014). King and Boyatt (2014) had identified that among factor, that being considered by students as well as higher education institutions during their opt for e-learning is the factor of technology from the perspective of infrastructure. The facility that assists an easy access to e-learning and visualization technology in e-learning are among the main factors of satisfaction with e-learning (Martin-Rodriguez et al., 2014). According to Capece and Campisi (2013), technology from the aspect of ease of use also affecting the motivation of adapting for e-learning.

In the knowledge age, students are heavy exposes toward e-learning. E-learning renders a greater beneficial effect on directing and shaping the future way of learning (Cappel \& Hayen, 2004; Capece \& Campisi, 2011). Thus, an extensive exposure to this online learning approach has been pushed into the education system. The degree of exposure from the side of the users about e-learning is among the critical success factors in proposing university curriculums that compromise e-learning-based courses (Selim, 2007). Experience being exposed toward e-learning is also considered as one of the main features for sample that involves in online learning studies (Mondi, Woods, \& Rafi, 2008).

Content is among major e-learning usage motivational factors. Al-Samarraie, Teo, and Abbas (2013) find that content is interrelated to motivation in practice of e-learning. They found that motivation, attention as well as interactivity as the elements that affect students' thinking skills in understanding e-learning content. However, this research was conducted under a standardized e-learning environment for all samples. In a personalized-based e-learning, Senthil-Kumaran and Sankar (2013) found that content is also a motivational factor in adapting to e-learning. They believed that content can be more effective when being customized according to individual needs as it boost proactive delivery to the users. This scenario deliberately enhanced users' motivation in using e-learning. Content when being tailored carefully can further intensify e-learning user motivation to use e-learning, according to Calli et al. (2013), content effectiveness had a significant effect on perceived usefulness by the users. Content richness in e-learning has been identified as extrinsic factors in the inquiry model of e-learning (Lee \& Faulkner, 2011).

$\mathrm{Wu}$ and Zhang (2014) based on their empirical study show that social influence had no significant effect on e-learning usage. The finding was further sustained by Lin and Yang (2012) as their questionnaire-based study disclosed that social influence is not impacting e-learning usage. Yet, Lin and Yang found that social presence is a strong predictor of influence in e-learning usage. In a university setting, social influence is affecting e-learning usage motivation (Hernandez et al., 2011). Indeed, the presence of social influence had further improved user intentions for continuous application of e-learning. The differences in demographic and geographical landscape between Wu and Zhang (2014), Lin and Yang (2012) and Hernandez et al. (2011) that cause different culture and environment might explain the disparity between their finding. Social interactions that presence in e-learning plays a significant role in the usage of e-learning (Lee \& Faulkner, 2011) as social influence was found to be having a positive influence over users' behavioral intention (Maldonado et al., 2011).

According to the literature review done on this focus, four factors named as the factors of technology, exposure, content and social influence are perceived as the motivational factors of e-learning usage. The factor of technology is seen as the most dynamic and complex as it not only involves the technology in e-learning interaction itself, but, also involving the element of ease of access as well as facility technology in supporting this web 2.0 practice. However, little has been written on the motivational factors of e-learning usage among educational technology postgraduate students. As mean of filling-up the research gap exists, the researcher had used the four aforementioning factors as the fundamental factors to be investigated. The four factors will be evaluated either stand-in as the motivational factors toward the usage of e-learning among educational technology postgraduate students or not.

\subsection{Social Media Usage Motivational Factors}

Perceived mobility, connectedness and security are among the identified motivational factors for social media usage in South Korea (Kwon, Park, \& Kim, 2014). Mobility of social networking sites when is setting up in a circumstance that emphasize the ease of use impact the usage of social media significantly, also, it significantly influences user behavioral intention (Nikou \& Bouwman, 2014). Technology (e.g. smartphone and tablet) that enable flexible mobility of the social networking site render ease access to social media and therefore make user been using it for a longer time. Social media has been detected as the factor influencing the adoption for smart 
phone in Malaysia (Pee, Maksum, \& Norizan, 2014).

Exposure from lecturer to use social networking site as a mean of communication motivated user to use social media (Helou \& Ab. Rahim, 2014). Teacher active use of social networking technologies as an educational tool, enhanced creativity (Norlidah et al., 2013) which mark the exposure as beneficial.

Overloading content in social media might cause social media fatigue (Bright, Kleiser, \& Grau, 2015). Nevertheless, right content coordination appeal specific bracket of users (Lo, Cornforth, \& Chiong, 2015). Volume of comment on a generated content indicates how well it had attracted attention (Balali et al., 2013). Public institutions such as university are now actively using social networking sites to engage its customer, the content of posts published by university actually boosts interaction (Frey et al., 2013).

Social factor such as wish to read friends' post do drive university students use social networking site (Nam, 2012). Thus, it seems that extroverted individual is more likely to read friends' post. Yet, extroverted individuals are no more likely to read friends' post than normal individuals (Glynn, Huge, \& Hoffman, 2012).

Four factors are identified as motivating factors toward the usage of social media. Again, little has been explored about the motivational factors of social networking usage among educational technology postgraduate students. In addition, The relationship between the usage of e-learning and social networking site among educational postgraduate students is still unclear.

\section{Related Work}

The adoption rate of e-learning is related to the motivational and behavioral trait of its user (Schneckenberg, 2009). He further suggests that institutional effort to adopt e-learning must be taken into the motivational factor of user in its attention. Introduction of Computer Assisted Learning (CAL) had paved way for multiple options of digital learning material (Ahmad \& Mutalib, 2015), which render the need for motivational factor to be given a serious attention.

As the dropout rate of e-learning is high, Rostaminezad et al. (2012) probed into the theories that explain the success rate of learner in e-learning setting. The content analysis of 24 major researches relating to e-learning shows that motivational theories, self-regulated learning and interaction are the foremost theory behind the success of e-learner. Unfortunately, no further in detail research on motivational factors has been conducted.

The usage of Twitter is correlated positively with internal motivation (Sweetser \& Kelleher, 2011). The linking on Facebook is being influenced by the motivation of information sharing (Baek et al., 2011). In Thailand, external factors are more dominant than internal factors in affecting social media motivation (Pornsakulvanich \& Dumrongsiri, 2013). However, what is the motivational factor to use social media in education setting?

\section{Methodology}

\subsection{Research Questions}

The research has been conducted to answer the following research questions:

1) Are the factors of technology, exposure, content and social influence does motivate the usage of social media and e-learning among educational technology postgraduate students?

2) Is there is any relationship between the usage of e-learning and the usage of social media among educational technology postgraduate students?

In this study, the researchers had implemented cross-sectional survey research design. The data were analyzed using both descriptive and inferential statistics approach. However, the descriptive part of this research is not being elaborated in this paper and only being summarized using inferential data output.

\subsection{Sample and Population}

The population for this research is educational technology postgraduate students from the Faculty of Education, Universiti Teknologi Malaysia. For the purpose of this research, 170 respondents have been sampled based on the sample size stated by Krijcie and Morgan (1990). Respondents were sampled using random sampling techniques.

\subsection{Research Instrument}

Data were collected using a questionnaire named as Social Media and e-Learning among Postgraduate Students Questionnaire. There are three parts of the instrument labeled as Part A, Part B and Part C. There are also four constructs in the questionnaire which are e-learning usage, social media usage, motivational factors toward the usage of e-learning and motivational factor toward the usage of social media. The instrument was designed using 
5 point Likert's scales with 5 as very frequent, 4 frequent, 3 as moderate, 2 as rarely and 1 as never for construct e-learning usage and social media. Another two construct also uses 5 points Likert's scales with 5 as strongly agree, 4 as agree, 3 as moderate, 2 as disagree and lastly 1 as strongly disagree. The instrument was found to be highly reliable with a reliability coefficient of 0.79 using Cronbach's Alpha via internal consistency technique. The pilot study involved 12 respondents that are not a part of the sampled respondents. The validity of the instrument has been verified by two experienced lecturers who are teaching for more than 8 years.

\subsection{Data Analysis Technique}

How data for each research question were analyzed has been summarized in Table 1. All the data from the questionnaire are treated as ratio data.

Table 1. Research objective and data analysis technique

\begin{tabular}{ll}
\hline Research Question & Data Analysis Technique \\
\hline $\begin{array}{l}\text { Are the factors of technology, exposure, content and social influence does } \\
\text { motivate the usage of social media and e-learning among educational }\end{array}$ & Structural Equational Modeling \\
technology postgraduate students? & \\
$\begin{array}{l}\text { Is there is any relationship between the usage of e-learning and the usage } \\
\text { of social media among educational technology postgraduate students? }\end{array}$ & Spearman's Rho Correlation Test \\
\hline
\end{tabular}

Confirmatory Factor Analysis (CFA) was not conducted as this research is not proposing for hypothesis model. The research focus is to identify the motivational factors of e-learning and social media usage. Therefore, there is no need for CFA to be piloted (Chua, 2014).

The relationship between the usage of e-learning and the usage of social media was inspected using Spearman's rho test as the instrument used in this research, Social Media and e-Learning among Postgraduate Students Questionnaire is using Likert's scale technique that make it as not normally distributed in nature. Therefore, it need non-parametric test.

\section{Findings}

\subsection{Structural Equation Model for E-learning Usage}

SEM has been conducted by e-learning usage as endogenous variable and technology factor, exposure factor, content factor and social influence factor as exogenous variables. The analysis was made based on the following hypothesis

Null Hypothesis: The factor of technology, exposure, content and social influence are not the motivational factors for e-learning usage among educational technology postgraduate students in the Faculty of Education, Universiti Teknologi Malaysia.

Research Hypothesis: The factor of technology, exposure, content and social influence are the motivational factors for e-learning usage among educational technology postgraduate students in the Faculty of Education, Universiti Teknologi Malaysia.

The regression model based on SEM analysis is as in Figure 1. 


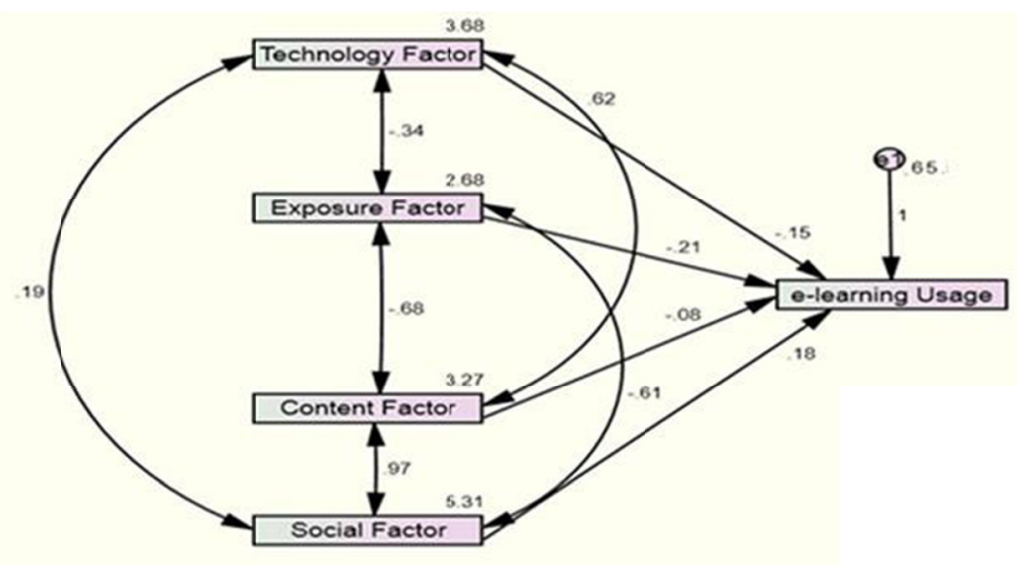

Figure 1. The regression model for e-learning usage and its motivational factors

The regression model in Figure 1 was reported to have 16 parameters with degree of freedom (df) equal to 0 . Hence, the $\chi^{2}$ value of goodness of fitness can not be calculated. The regression weight for data in Figure 1 is as in Table 2.

Table 2. The regression weight for regression model for e-learning usage and its motivational factors

\begin{tabular}{lllll}
\hline & Estimate & S.E. & C.R. & P \\
\hline e-learning usage $\leftarrow-$ technology factor & -.151 & .164 & -1.99 & $* * *$ \\
e-learning usage $\leftarrow-$ exposure factor & -.207 & .196 & -1.57 & .291 \\
e-learning usage $\leftarrow-$ content factor & -0.76 & .181 & -1.97 & $* * *$ \\
e-learning usage $\leftarrow-$ social influence factor & .175 & .139 & 1.262 & .207 \\
\hline
\end{tabular}

Data in Table 2 was analyzed using path analysis technique. Critical ration (C.R) value outside the range of \pm 1.96 is considered as significant at level $p<.05$. Therefore, the regression between e-learning usage and technology factor as well as the regression between e-learning usage and content factor are significant. The other two factors are not having significant regression toward e-learning usage. The regression weight in Table 2 then being standardized as standardized regression weight, $\beta$ as in Table 3 .

Table 3. The standardized regression weight for regression model for e-learning usage and its motivational factors

\begin{tabular}{lc}
\hline & Estimate \\
\hline e-learning usage $\leftarrow-$ technology factor & -.110 \\
e-learning usage $\leftarrow-$ exposure factor & -.128 \\
e-learning usage $\leftarrow-$ content factor & -.052 \\
e-learning usage $\leftarrow-$ social influence factor & .153 \\
\hline
\end{tabular}

As illustrated by Table 2 and Table 3, there is a significant relationship between e-learning usage and technology factor $(\beta=-.110, \mathrm{C} . \mathrm{R}=-1.99, p<.05)$. Also, content factor has a significant effect on e-learning usage $(\beta=-$. $052, \mathrm{C} . \mathrm{R}=-1.97, p<.05)$. The factor of exposure $(\beta=-.128, \mathrm{C} . \mathrm{R}=-1.57, p=.291)$ and the factor of social influence $(\beta=.153, \mathrm{C} . \mathrm{R}=1.262, p=.207)$ has no significant influence toward respondent usage of e-learning.

Based on the regression model in Figure 1, the squared multiple correlations value is equal to 0.65 . Using the formula e $1=1$ - estimate squared multiple correlation value, which is e $1=1-0.65=0.35$. Indicating 35 percent variance in variable e-learning usage cannot be predicted by the regression model as in Figure 1. 


\subsection{Structural Equation Model for Social Media Usage}

Social media usage has been set as endogenous variable and technology factor, exposure factor, content factor and social influence factor as exogenous variables. The following hypothesis have been set as a guideline to the SEM analysis.

Null Hypothesis:

The factor of technology, exposure, content and social influence are not the motivational factors for social media usage among educational technology postgraduate students in the Faculty of Education, Universiti Teknologi Malaysia.

Research Hypothesis: The factor of technology, exposure, content and social influence are the motivational factors for e-learning usage among educational technology postgraduate students in the Faculty of Education, Universiti Teknologi Malaysia.

The regression model as the result of SEM is as in Figure 2.

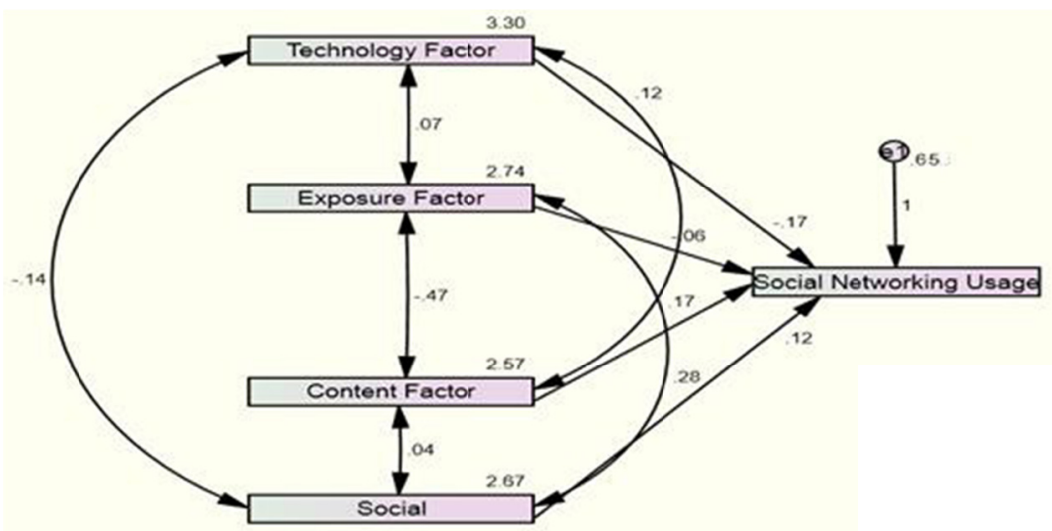

Figure 2. The regression model for social networking usage and its motivational factors

The regression model in Figure 2 was reported to have 16 parameters. df was found to be 0 , thus, $\chi^{2}$ value of goodness of fitness cannot be premeditated. Regression weight data for regression model for social media usage and its motivational factors is as in Table 3 and standardized regression weight value as in Table 4.

Table 4. The regression weight for regression model for social media usage and its motivational factors

\begin{tabular}{lcccc}
\hline & Estimate & S.E. & C.R. & P \\
\hline social media usage $\leftarrow-$ technology factor & -1.69 & .170 & -1.99 & .030 \\
social media usage $\leftarrow-$ exposure factor & -.055 & .190 & -.291 & .771 \\
social media usage $\leftarrow-$ content factor & .174 & .195 & .891 & .373 \\
social media usage $\leftarrow-$ social influence factor & .124 & .189 & 2.65 & .050 \\
\hline
\end{tabular}

According to output from Table 4, the regression between the technology factor and social media usage and the regression between social influence factor and the social media usage are significant. The other two factors are not significant. The standardized regression weigh, $\beta$ for data in Table 4 is as in Table 5 . 
Table 5. The standardized regression weight for regression model for social media usage and its motivational factors

\begin{tabular}{lr}
\hline & Estimate \\
\hline social media usage $\leftarrow-$ technology factor & -.118 \\
social media usage $\leftarrow-$ exposure factor & -.035 \\
social media usage $\leftarrow-$ content factor & .107 \\
social media usage $\leftarrow-$ social influence factor & .078 \\
\hline
\end{tabular}

As illustrated by Table 4 and Table 5, there is a significant relationship between social media usage and technology factor $(\beta=-.118, \mathrm{C} . \mathrm{R}=-1.99, p<.05)$. The social influence factor is also found to be having a significant effect on social media usage $(\beta=.078, \mathrm{C} . \mathrm{R}=2.65, p<.05)$. The factor of exposure $(\beta=-.035, \mathrm{C} . \mathrm{R}=$ $-.291, p=771)$ and the factor of content $(\beta=.107, \mathrm{C} . \mathrm{R}=.891, p=.373)$ has no significant influence toward respondent usage of social media.

Based on the regression model in Figure 2, the squared multiple correlations value is equal to 0.65 . Then, the e1 is equal to 0.35 . Meaning that 35 percent of the variance can not be forecasted by the regression model as in Figure 2.

\subsection{The Relationship Between the Usage of E-learning and the Usage of Social Networking Site}

As mean of studying the relationship between the usage of e-learning and the usage of social media, the researcher had implemented Spearman's rho test. The result of the test is as in Table 6.

Table 6 . The correlation between the usage of e-learning and the usage of social media

\begin{tabular}{|c|c|c|c|c|}
\hline & & & e-learning Usage & Social Media Usage \\
\hline \multirow[t]{5}{*}{$\begin{array}{l}\text { Spearman's } \\
\text { rho }\end{array}$} & \multirow{3}{*}{$\begin{array}{l}\text { e-learning } \\
\text { Usage }\end{array}$} & $\begin{array}{l}\text { Correlation } \\
\text { Coefficient }\end{array}$ & 1.000 & $0.982 * *$ \\
\hline & & Sig. (2-tailed) & & .000 \\
\hline & & $\mathrm{N}$ & 70 & 70 \\
\hline & \multirow[t]{2}{*}{$\begin{array}{l}\text { Social } \\
\text { Media } \\
\text { Usage }\end{array}$} & $\begin{array}{l}\text { Correlation } \\
\text { Coefficient } \\
\text { Sig. (2-tailed) }\end{array}$ & $\begin{array}{c}0.982 * * \\
.000\end{array}$ & 1.000 \\
\hline & & $\mathrm{N}$ & 70 & 70 \\
\hline
\end{tabular}

$* * p<.01$.

Based on the result of Spearman's rho test as in Table 6 , for respondent in this research $(n=70)$, the strength of correlation between the usage of e-learning and the usage of social media is strong $\left(\mathrm{r}_{\mathrm{s}}=0.982\right), p=0.000, p<$ 0.01. There is a strong, positive relationship between the e-learning usage and social media usage.

\section{Discussion}

Four factors were believed to influence the usage of web-based environment are technology (Sun \& Bhattacherjee, 2014), exposure (Riendl et al. 2014), content (Choi, Moon, \& Nae, 2014) and social influence (Uusiaitti \& Maatta, 2014). Yet, the finding of this research suggests that only the factor of technology and social influence are influencing respondents' usage of e-learning. Indicating that respondent usage of the e-learning is mainly as the result of peripheral stimulation from friends and university environment. Mainly due to the facilities prepared for e-learning integration. Cheng (2014) found extrinsic motivator does affect the usage of e-learning. Zhao and Kemp (2013) had included the factor of support by organization and social exchange and social capital in their model on web 2.0 learning. This further supports the finding of this research.

Nikou and Bouwman (2014) found that the usage of social media is influenced by the ease of use and the context of the social networking site including the social influence of the users. The mobility of the nowadays social networking site and its ability to make individual connected to the outside world render it as motivational factors to keep using it (Kwon, Park, \& Kim, 2014). Request from friend contributes to the usage of social networking 
as the sustainability of social networking depending on it (Chang et al., 2014).

E-learning based on Learning Management System is rigid in nature (Rodrigues, Sabino, \& Zhou, 2011). While, social networking has the ability to overcome the limitation of relationship and interaction in e-learning (Rodrigues, Sabino, \& Zhou, 2011). The social media can be utilized as a mechanism of facilitating the achievement of learning objectives. The strong relationship indicates social media can influence the usage of e-learning. Therefore, social networking site can be used as complimentary material toward e-learning, but not replacing the e-learning $(\mathrm{Li}$, Ganeshan, \& Xu, 2012). As a social media has its own strong persuasive power, its integration with e-learning may further synergize the impact of e-learning toward the user.

The social networking site has been very popular among the respondents. Han, Nelson, and Wetter (2014) find that social networking tools does not beneficial to its user learning despite of frequent use by the users. This finding also was supported by Jong et al. (2014) who suggests that students use social networking to enhance social connectedness, but seldom for educational purposes. In contrast to the e-learning application usage, chatting and messaging are the most frequent use application on social networking site. This might be due to respondents are having the perspective that chatting and messaging on social networking as the main channel of communication (Adediran \& Kehinde, 2013).

\section{Conclusion and Suggestion}

The motivational factors for e-learning usage among educational postgraduate students are the factor of technology and content. The factor of technology and social influence motivates the sample to use social media.

It is highly suggested that for educational plan, organization as well as the policy maker must highlight technology element into their attention. A close consideration to the element of technology might ensure a higher percentage for effective implementation. Emphasization on the factor of technology among the educational technology students suggests that technology might be the bridge to integrate e-learning and social media in educational settings.

To motivate students to use e-learning, the content of the e-learning must be suitable and attractive to the user. To implement social media, support toward social influence might foster the use of social media in learning.

\section{Acknowledgments}

The authors would like to thank Universiti Teknologi Malaysia (UTM) and Ministry of Education (MoE) Malaysia for their support in making this project possible. This work was supported by PAS Grant (Q.J130000.2731.00K81) initiated by UTM and MoE.

\section{References}

Adediran, E. M. T., \& Kehinde, A. O. (2013). Gender and internet use pattern of pre-service teachers in a Nigerian college of education. Mediterranean Journal of Social Sciences, 4(15), 151-158. http://dx.doi.org/10.5901/mjss.2013.v4n16p151

Ahmad, S. Z., \& Mutalib, A. A. (2015). Exploring Computer Assisted Learning for Low Achieving Children: A Comparative Analysis Study. Jurnal Teknologi, 77(29), 1-7. http://dx.doi.org/10.11113/jt.v77.6803

Al-Samarraie, H., Teo, T., \& Abbas, M. (2013). Can structured representation enhance students' thinking skills for better understanding of E-learning content? Computers and Education, 69, 463-473. http://dx.doi.org/10.1016/j.compedu.2013.07.038

Aris, B., Gharbaghi, A., Ahmad, M. H., \& Rosli, M. S. (2013). A checklist for evaluating persuasive features of

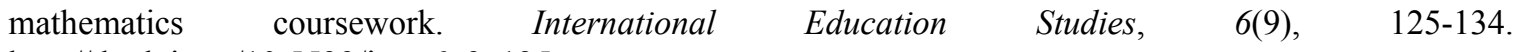
http://dx.doi.org/10.5539/ies.v6n9p125

Baek, K., Holton, A., Harp, D., \& Yaschur, C. (2011). The Links That Bind: Uncovering Novel Motivations for Linking on Facebook. Computers in Human Behavior, 27(6), 2243-2248. http://dx.doi.org/10.1016/j.chb.2011.07.003

Balali, A., Rajabi, A., Ghassemi, S., Asadpour, M., \& Faili, H. (2013). Content diffusion prediction in social networks. IKT $2013-20135^{\text {th }}$ Conference on Information and Knowledge Technology (pp. 467-471). http://dx.doi.org/10.1109/ikt.2013.6620114

Bian, J., Long, B., Li, L., Moon, T., Dong, A., \& Chang, Y. (2014). Exploiting user preference for online learning in web content optimization system. ACM Transactions on Intelligent System and Technology, 5(2), 33:1-33:23. http://dx.doi.org/10.1145/2493259

Bright, L. F., Kleiser, S. B., \& Grau, S. L. (2015). Too much Facebook? An exploratory examination of social 
media fatigue. Computer in Human Behavior, 44, 148-155. http://dx.doi.org/10.1016/j.chb.2014.11.048

Calli, L., Balcikanli, C., Calli, F., Cebeci, H. I., \& Seymen, O. F. (2013). Identifying factors that contribute to the satisfaction of students in e-learning. Turkish Online Journal of Distance Education, 14(1), 85-101.

Capece, G., \& Campisi, D. (2013). User satisfaction affecting the acceptance of an e-learning platform as a mean for the development of the human capital. Behaviour \& Information Technology, 32(4), 335-343. http://dx.doi.org/10.1080/0144929X.2011.630417

Cappel, J. J., \& Hayen, R. L. (2004). Evaluating e-learning: A case study. Journal of Computer Information Systems, 44(4), 49-56.

Castillo-Merino, D., \& Serradell-Lopez, E. (2014). An analysis of the determinants of students' performance in e-learning. Computers in Human Behavior, 30(1), 476-484. http://dx.doi.org/10.1016/j.chb.2013.06.020

Chang, C.-C., Hung, S.-W., Cheng, M.-J., \& Wu, C-Y. (2014). Exploring the intention to continue using social networking sites: The case of Facebook. Technological Forecasting and Social Change (In Press). https://dx.doi.org/10.1016/j.techfore.2014.03.012

Cheng, Y-M. (2014). Roles of Interactivity and usage experience in e-learning acceptance: A longitudinal study. International Journal of Web Information System, 10(1), 2-23. https://dx.doi.org/10.1108/IJWIS-05-2013-0015

Choi, B. K., Moon, H. K., \& Nae, E. Y. (2014). Cognition and affect based trust and feedback-seeking behavior: The roles of value, cost, and goal orientations. Journal of Psychology: Interdisciplinary and Applied, 148(5), 603-620. https://dx.doi.org/10.1080/00223980.2013.818928

Chua, Y. P. (2014). Research Methodology and Statistics: Regression Test, Factor Analysis and SEM Analysis. Shah Alam, Malaysia: McGraw Hill Education.

El-Seoud, M. S. A., Ghenghesh, P., Seddiek, N., Nosseir, A., Taj-Eddin, I. A. T. F., \& El-Khouly, M. M. (2013). E-Learning and motivation effects on Egyptian higher education. International Journal of Emerging Technologies in Learning, 9(4), 20-26. http://dx.doi.org/10.3991/ijet.v9i4.3465

Frey, J.-C., Ebner, M., Schon, M., \& Taraghi, B. (2013). Social media usage at universities: How should it be done? WEBIST 2013-Proceedings of the 9th International Conference on Web Information Systems and Technologies (pp. 608-614).

Gewerc, A., Montero, L., \& Lama, M. (2014). Collaboration and social networking in higher education. Comunicar, 21(42), 55-62. http://dx.doi.org/10.3916/C42-2014-05

Giesbers, B., Rienties, B., Tempelaar, D., \& Gijselaers, W. (2014). A dynamic analysis of the interplay between asynchronous and synchronous communication in online learning: The impact of motivation. Journal of Computer Assisted Learning, 30(1), 30-50. http://dx.doi.org/10.1111/jcal.12020

Han, H., Nelson, E., \& Wetter, N. (2014). Medical students' online learning technology needs. Clinical Teacher, 11(1), 15-19. http://dx.doi.org/10.1111/tct.12092

Helou, A. M., \& Ab. Rahim, N. Z. (2014). The influence of social networking sites on students' academic performance in Malaysia. International Journal of Electronic Commerce Studies, 5(2), 247-254. http://dx.doi.org/10.7903/ijecs.1114

Hernandez, B., Montaner, T., Sese, J., \& Urquizu, P. (2011). The role of social motivations in e-learning: How do they affect usage and success of ICT interactive tools? Computers in Human Behavior, 27(6), 2224-2232. http://dx.doi.org/10.1016/j.chb.2011.07.001

Hu, L.-T., \& Bentler, P. M. (1999). Cutoff criteria for fit indexes in covariance structure analysis: Conventional criteria versus new alternatives. Structural Equation Modeling, 6(1), 1-55. http://dx.doi.org/10.1080/10705519909540118

Ismail, I., Idrus, R. M., Baharum, H., Rosli, M., \& Ziden, A. A. (2011). The learners' attitudes towards using different learning methods in e-learning portal environment. International Journal of Emerging Technologies in Learning, 6(3), 49-52. http://dx.doi.org/10.3991/ijet.v6i3.1407

Jong, B.-S., Lai, C.-H., Hsia, Y.-T., \& Liao, Y.-S. (2014). An exploration of the potential educational value of Facebook. Computers in Human Behavior, 32, 201-211. http://dx.doi.org/10.1016/j.chb.2013.12.007

King, E. \& Boyatt, R. (2014). Exploring factors that influence adoption of e-learning within higher education. British Journal of Educational Technology (In Press). https://dx.doi.org/10.1111/bjet.12195 
Kwon, S. J., Park, E., \& Kim, K. J. (2014). What drives successful social networking services? A comparative analysis of user acceptance of Facebook and Twitter. Social Science Journal (In press). https://dx.doi.org/10.1016/j/soscij.2014.04.005

Kwon, S. J., Park, E., \& Kim, K. J. (2014). What drives successful networking services? A comparative analysis of user acceptance of Facebook and Twitter. The Social Science Journal, 51(4), 534-544. http://10.1016/j.soscij.2014.04.005

Lee, R., \& Faulkner, M. (2011). The roles of extrinsic factors in a community of inquiry model of e-learning. E-Learning and Digital Media, 8(1), 58-67. http://dx.doi.org/10.2304/elea.2011.8.1.58

Lesko Jr., C. J. (2012). Integration of virtual immersive environments as an interactive collaboration medium: A case study in student perceptions. Computers in Education Journal, 22(1). 66-85.

Li, X., Ganeshan, K., \& Xu, G. (2012). The role of social networking sites in e-learning. Proceedings of Frontiers in Education Conference, 42, 6462424. http://dx.doi.org/10.1109/FIE.2012.6462424

Lin, C.-H., \& Yang, S.-C. (2012). Factors that influence students' satisfaction and performance in e-learning environments. Technics Technologies Education Management, 7(3), 1107-1114.

Lo, S. L., Cornforth, D., \& Chiong, R. (2015). Use of a high-value social audience index for target audience identification on Twitter. Lectures Notes in Computer Science, 8955, 323-336. http://dx.doi.org/10.1007/978-3-319-14803-8_25

Marco, F. A., Penichet, V. M. R., \& Gallud, J. A. (2013). Collaborative e-learning through drag\&share in synchronous shared workspaces. Journal of Universal Computer Science, 19(7), 894-911.

Martin-Rodriguez, O., Fernandez-Molina, J. C., Montero-Alonso, M. A., \& Gonzalez-Gomez, F. (2014). The main components of satisfaction with e-learning. Technology, Pedagogy and Education (In Press). https://dx.doi.org/10.1080/1475939X.2014.888370

Nam, S-Z. (2012). Korean university students' utilization of social networking systems. Lectures Notes in Electrical Engineering, 179(2), 331-336. https:// 10.1007/978-94-007-5064-7_46

Nikou, S., \& Bouwman, H. (2014). Ubiquitous use of mobile social network services. Telematics and Informatics, 31(3), 422-433. https://dx.doi.org/10.1016/j.tele.2013.11.002

Norlidah, A., Saedah, S., Mohd-Khairul, A. M. D., \& Zaharah, H. (2013). Effectiveness of Facebook Based Learning to Enhance Creativity among Islamic Studies Students by Employing Isman Instructional Design Model. Turkish Online Journal of Educational Technology, 12(1), 60-67.

Pee, N. C., Maksom, Z., \& Norizan, A. R. (2014). Factor influencing the use of smart phone by Malaysian's elderly. Journal of Theoretical and Applied Information Technology, 59(2), 421-425.

Pornsakulvanich, V., \& Dumrongsiri, N. (2013). Internal and External Influences on Social Networking Site Usage in Thailand. Computers in Human Behavior, 29(6), 2788-2795. http://dx.doi.org/10.1016/j.chb.2013.07.016

Pumper, M. A., Yaeger, J. P., \& Moreno, M. A. (2013). Perceptions and Use of Social Networking Sites in the United States and Ecuador: A Mixed-Methods Approach. College Students Journal, 47(3), 478.

Reindl, R., Mohr, P., Kenning, P., Davis, F., \& Heekeren, H. (2014). Trusting humans and avatars: A brain imaging study based on evolution theory. Journal of Management Information System, 30(4), 83-114. https://dx.doi.org/10.2753/MIS0742-1222300404

Rodrigues, J. J. P. C., Sabino, F. M. R., \& Zhou, L. (2011). Enhancing e-learning experience with online social networks. IET Communications, 5(8), 1147-1154. http://dx.doi.org/10.1049/iet-com.2010.0409

Rostamiezad, M. A., Mozayani, N., Norozi, D., \& Iziy, M. (2013). Factors related to e-learner dropout: Case study of IUST e-learning centre. Procedia-Social and Behavioral Sciences, 83, 522-527. http://dx.doi.org/10.1016/j.sbspro.2013.06.100

Schneckenberg, D. (2009). Understanding the Real Barrier to Technology-Enhanced Innovation in Higher Education. Educational Research, 51(4), 411-424. http://dx.doi.org/10.1080/00131880903354741

Selim, H. M. (2007). E-learning critical success factors: an exploratory investigation of student perceptions. $\begin{array}{lllll}\text { International Journal of Technology } & \text { Marketing, } & \text { 2(2), }\end{array}$ http://dx.doi.org/10.1504/IJTMKT.2007.014791

Senthil-Kumaran, V., \& Sankar, A. (2013). Study of personalization in E-learning. International Review on 
Computers and Software, 8(5), 1209-1217.

Song, K.-S., Nam, S. C., Lim, H. K., \& Kim, J. K. (2013). Analysis of youngster's media multitasking behaviors and effect on learning. International Journal of Multimedia and Ubiquitous Engineering, 8(4), 191-198.

Sozcu, O. F. (2014). The relationships between cognitive style of field dependence and learner variables in e-learning instruction. Turkish Online Journal of Distance Education, 15(2), 117-144. http://dx.doi.org/10.17718/tojde.11039

Stein, C. D., Eisenberg, E. S., O’Donnell, J. A., \& Spallek, H. (2014). What dental educators need to understand about emerging technologies to incorporate them effectively into the education process. Journal of Dental Education, 78(4), 520-529.

Sun, Y., \& Bhattacherjee, A. (2014). Looking inside the "black box: Technological effects on IT usage. Journal of Computer Information Systems, 54(2), 1-15.

Sweetser, K. D., \& Kelleher, T. (2011). A Survey of Social Media Use, Motivation and Leadership Among Public Relations Practitioners. Public Relations Review, 37(4), 425-428. http://dx.doi.org/10.1016/j.pubrev.2011.08.010

Uusiautti, S., \& Maata, K. (2014). I am no longer alone-how do university students perceive the possibilities of social media? International Journal of Adolescence and Youth, 19(3), 293-305. https://dx.doi.org/1080/02673843.2014.919600

Wu, B., \& Zhang, C. (2014). Empirical study on continuance intentions towards E-Learning 2.0 systems. Behaviour and Information Technology, http://dx.doi.org/10.1080/0144929X.2014.934291

Zhao, F., \& Kemp, L. (2013). Exploring individual, social and organizational effects on Web 2.0-based workplace learning: A research agenda for a systematic approach.

\section{Copyrights}

Copyright for this article is retained by the author(s), with first publication rights granted to the journal.

This is an open-access article distributed under the terms and conditions of the Creative Commons Attribution license (http://creativecommons.org/licenses/by/3.0/). 